\title{
Doze motivos favoráveis à adoção do Exame Nacional do Ensino Médio (ENEM) pelas Instituições Federais de Ensino Superior (IFES)
}

Wagner Bandeira Andriola*

\section{Resumo}

0 texto aborda alguns motivos favoráveis à adoção do Exame Nacional do Ensino Médio (ENEM) pelas Instituições Federais de Ensino Superior (IFES) como mecanismo de seleção dos seus candidatos. Com esse fim, traz breve histórico do exame do ENEM, suas principais características e diferenças marcantes com respeito ao novo modelo de ENEM proposto pelo Ministério da Educação (MEC). Os principais motivos favoráveis ao novo ENEM foram organizados com base nas seguintes demandas: a) uma nova sociedade que está em constante transformação e que é afetada pelas rápidas mudanças científicas; b) uma Universidade que acalenta por ter um universitário que saiba fazer uso inteligente, racional e inovador de informações oriundas dos rápidos avanços científicos e tecnológicos; c) um país que necessita incrementar substancialmente a proporção de jovens entre 18 e 24 anos no Ensino Superior. Palavras-chave: Ensino superior. Universidade. Avaliação educacional.

\section{Twelve reasons for the adoption of the National Examination for Secondary Education (ENEM) by Federal Institutions of Higher Education (IFES) Abstract}

The text discusses some reasons in favor of the adoption of the National Examination of Secondary Education (ENEM) by Federal Institutions of Higher Education (IFES) as a mechanism for selecting their candidates. With this aim, it provides brief historical survey of ENEM, its main features and significant

* Psicólogo; Especialista em Psicometria e Mestre em Psicologia Social e do Trabalho, Universidade de Brasília (UnB); Doutor em Filosofia e Ciências da Educação, Universidad Complutense de Madrid; Professor Associado, Faculdade de Educação, Universidade Federal do Ceará (UFC); Coordenador de Avaliação Institucional, UFC; Membro da Associação Brasileira de Avaliação Educacional (ABAVE); Bolsista de Produtividade em Pesquisa (CNPq). E-mail: w_andriola@ufc.br. 
differences regarding the new model of ENEM proposed by the Ministry of Education (MEC). The main reasons in favor of the new ENEM were organized based on the following requests: a) a new society that is constantly changing and is affected by rapid scientific changes; b) a University that cherishes for having a student who knows how to make use of intelligent rational and innovative information from the rapid advances in science and technology; c) a country that needs to substantially increase the proportion of 18 to 24 years old people in higher education.

Keywords: Higher education. University. Educational assessment.

\section{Doce motivos favorables a la adopción del Examen Nacional de la Enseñanza de Nivel Medio (ENEM) por las Instituciones Federales de Enseñanza de Nivel Superior (IFES) Resumen}

El artículo aborda algunos motivos favorables a la adopción del Examen Nacional de la Enseñanza de Nivel Medio (ENEM) por parte de las Instituciones Federales de Enseñanza de Nivel Superior (IFES) como mecanismo de selección de los candidatos. Para ello, se presenta breve histórico del ENEM, sus principales características y las principales diferencias respecto al nuevo modelo del ENEM propuesto por el Ministerio de Educación (MEC). Los principales motivos favorables al nuevo ENEM se organizaron a partir de las siguientes demandas: a) una sociedad que está en constante cambio y que se ve afectada por las rápidas transformaciones cientificas; b) una Universidad que desea un universitario que sepa hacer uso inteligente, racional e innovador de las informaciones oriundas de los avances científicos y tecnológicos; c) un pais que necesita incrementar sustancialmente la proporción de jóvenes entre 18 y 24 años en la Enseñanza de Nivel Superior.

Palabras clave: Enseñanza superior. Universidad. Evaluación educacional.

\section{Introdução}

0 número 12 sempre exerceu fascínio sobre a humanidade. Na Grécia antiga, mãe da civilização e da filosofia ocidentais, havia vários mitos que versavam sobre deuses, semideuses e heróis. 0 mito de Hércules relata 12 trabalhos impossiveis para os simples mortais, que, não obstante, foram executados pelo protagonista, sob o comando de Euristeu, Rei de Argos de Micenas.

Há cerca de 2.000 anos, na região da Palestina, um homem chamado Jesus Cristo escolheu 12 discípulos, aos quais denominou Apóstolos, para iniciar um dos 
maiores movimentos sociais de todos os tempos, que deu origem à Igreja Católica Apostólica e Romana. A missão dos Apóstolos era dar prosseguimento aos ensinamentos de Jesus Cristo, e trazer para o mundo material (os quadrantes do mundo) o lado espiritual da vida (a Divina Trindade). Curiosamente: $4 \times 3=12$. Dentre os vários milagres de Jesus Cristo há um que apresenta uma curiosidade que nos interessa. No milagre da multiplicação dos pães, o Apóstolo Mateus destacou que 12 cestos foram cheios com as sobras (Mateus, capítulo 14, versículo 20).

Mais recentemente, em 1582, o Papa Gregório XIII promulgou um novo calendário adotado atualmente pelos paises ocidentais e por muitos paises orientais, em substituição ao calendário Juliano (proposto pelo Imperador Romano Júlio César, em 46 a.C.). 0 novo calendário organizou a medida temporal que a Terra leva para dar um giro completo ao redor do Sol em 12 meses.

Há que se destacar, ainda, o fato de o número 12 também ser ressaltado no Zodíaco, pela divisão da esfera celeste em 12 casas (ou signos), simbolizando que a regência do Universo é feita por uma Trindade sobre as quatro direções do mundo material. No que diz respeito à Climatologia, são quatro as estações, cada uma com duração de três meses. Em ambos os exemplos: $4 \times 3=12$.

Para arrematar a série de excentricidades e curiosidades envolvendo o número 12, vale ressaltar que, na Matemática, um número é considerado perfeito quando a soma dos seus divisores (incluindo o 1 e ele próprio) é igual ao dobro do seu próprio valor. Assim, 6 é o primeiro número perfeito, sendo 12 o dobro deste.

Os exemplos citados revelam o simbolismo do número 12, bem como o fascínio que este tem exercido sobre a humanidade, desde muitos séculos. Para não irmos de encontro a estas fabulosas crenças e, assim, honrarmos essa antiga tradição, apresentaremos, a seguir, 12 motivos favoráveis à adoção do Exame Nacional do Ensino Médio (ENEM) pelas Instituições Federais de Ensino Superior (IFES). Antes, porém, faremos breve histórico acerca das origens da Universidade na sociedade árabe, no velho mundo, na América e no Brasil, destacando as principais características dos processos adotados na seleção de discentes.

\section{Breve retrospectiva histórica acerca dos processos seletivos para a Universidade}

\section{Proto-história da Universidade}

A Universidade como espaço voltado à formação profissional e cidadã dos indivíduos, com base nas atividades de ensino, de pesquisa científica e de extensão, é fruto de uma construção social muito recente. Essa instituição educacional de nivel superior tem suas origens intimamente associadas a alguns fatos da história antiga, dentre os 
quais três se destacam: (i) o surgimento de círculos de formação, em Atenas (Grécia), cujo maior expoente foi, sem dúvida alguma, o filósofo Sócrates; (ii) a criação de um espaço formal rotulado de Academia, voltado à discussão e à reflexão de idéias sobre o mundo e sobre a sociedade, que teve em Platão o seu mentor; e (iii) a construção do Museu e da Biblioteca de Alexandria (Egito) por Alexandre Magno.

A esse respeito, cabe destacar, por oportuno, que Sócrates, nascido em Atenas (Grécia) em 470 a.C., recusou-se a ser reconhecido como um mestre que ensinava, tão somente. Ele não cessava em asseverar e repetir que nada sabia. No diálogo socrático, não há um mestre que comunica algo a um aluno. Há dois homens que se comunicam entre si, permitindo o surgimento de duas novas consciências, em pé de igualdade, na medida em que as duas consciências buscam o desconhecido, e se buscam, igualmente. 0 objetivo do diálogo socrático, que muito frequentemente acabava em uma indagação, uma pergunta, era precisamente o de permitir destruir ou converter o mestre num eterno discipulo, que aprende ao longo de toda a vida.

Platão, um dos mais notáveis discípulos de Sócrates, era um filósofo ateniense, nascido por volta de 427 a.C., que fundou em Atenas, no ano 387 a.C., uma Academia que levou o seu nome (Academia de Platão), cuja ênfase se deu sobre o ensino de Filosofia. Desde então, o termo Academia é sinônimo de espaço de formação e de geração de conhecimentos.

Com respeito à biblioteca da cidade de Alexandria (Egito), fundada por Alexandre 0 Grande em 332 a.C., foi um espaço sob o qual se constituiu o maior acervo de cultura e ciência existente na antiguidade, convertendo-se em notável legado para o desenvolvimento geral da humanidade. Há indícios históricos de que, fascinada pela leitura, a jovem e bela princesa Cleópatra visitava quase diariamente a pomposa biblioteca. Mesmo quando César, o grande Imperador Romano, ocupou a maior parte da cidade, no ano 48 a.C., Cleópatra, sua amante e protegida, o fazia acompanhá-la na busca de novas narrativas no interior da referida biblioteca. 0 conquistador romano, um homem das letras, ficara substancialmente impressionado com a desenvoltura cultural da jovem princesa egípcia. Posteriormente, entre os séculos II e I a.C., Alexandria assumiria ser, com todos os méritos, a capital do mundo helenístico, convertendo-se em um centro cosmopolita, por cujas ruas, praças e mercados, circulavam gregos, judeus, assírios, sírios, persas, árabes, babilônios, romanos, cartagineses, gauleses, iberos, dentre tantos outros povos e nações. Portanto, pode-se asseverar que foi naquela parte do mundo onde se delimitam as fronteiras entre o ocidente e o oriente que as primeiras concepções de Universidade foram sendo plasmadas, pouco a pouco, ao longo do tempo.

De fato, os historiadores apontam que foi no norte da África, na cidade de Fez, no Marrocos, no ano de 859 d.C. (séc. IX), que surgiu a primeira universidade do mundo moderno, cujo nome é Al-Karueein. Ainda no norte da África, na cidade do Cairo, no Egito, aproximadamente em 988 d.C. (séc. X), foi fundada a segunda mais antiga Universidade do 
mundo: Al-Azhar. Portanto, se é correto asseverar que foi na África que se originaram os primeiros grupos de humanos ascendentes do homo sapiens, igualmente correto é atribuir a gênese dos primeiros espaços universitários a este imenso continente.

No entanto, cumpre realçar, por oportuno: essas duas primeiras Universidades já traziam consigo a necessidade de adotar critérios para a seleção dos seus futuros alunos. Por exemplo, os alunos deveriam pertencer à religião muçulmana; deveriam ser varões; e deveriam ter posses, de modo a pagar as taxas acadêmicas. Vê-se, desse modo, a adoção de três critérios extremamente objetivos para selecionar os futuros universitários.

Na sociedade ocidental, a primeira Universidade foi fundada, no ano 1088 d.C. (séc. XI), na cidade italiana de Bolonha, quase 230 anos após o surgimento da primeira Universidade oriental. A segunda Universidade do mundo ocidental foi fundada em 1096 (séc. XI), na cidade de Oxford, na Inglaterra. Nestes dois casos, também, havia claros e objetivos critérios de seleção dos discentes, a saber: tinham que ser cristãos; deveriam ser varões; e deveriam ter posses, de modo a pagar as taxas acadêmicas.

\section{A universidade do Novo Mundo}

No Novo Mundo, as primeiras universidades foram fundadas logo após a chegada dos primeiros colonizadores espanhóis. Por exemplo, a Universidade Autônoma de Santo Domingo, na atual República Dominicana (América Central), foi fundada em 1538 (séc. XVI), constituindo-se na primeira universidade americana. Na América do Sul, a primeira universidade foi fundada pelos Jesuítas, em 1613 (séc. XVII), na cidade de Córdoba, na Argentina, sendo denominada de Universidade de Córdoba. Alguns anos depois, em 1636 (séc. XVII), a América do Norte fundou o seu primeiro espaço universitário: a Universidade de Harvard, localizada nos Estados Unidos da América, então colônia britânica. Igualmente como suas coirmãs européias, as universidades americanas também adotavam seus procedimentos de seleção de alunos, a saber: tinham que ser varões oriundos da nobreza; e tinham que ter posses, de modo a custear as taxas acadêmicas.

\section{A proto história da Universidade brasileira}

No Brasil, as primeiras Instituições de Ensino Superior (IES) somente vieram a surgir com a vinda da Família Real Portuguesa, no ano de 1808 (séc. XIX), em fuga dos exércitos napoleônicos. De fato, em 22 de janeiro de 1808, em Salvador, na Bahia, foi oficialmente criado o primeiro curso superior de Cirurgia, Anatomia e Obstetrícia. Alguns anos depois, em 11 de agosto de 1827, foram criadas duas Faculdades de Direito: uma na cidade de Olinda (Faculdade de Direito de Olinda), no estado de Pernambuco, que funcionou no Mosteiro de São Bento e que contou com alunos ilustres do porte de Rui Barbosa, Castro Alves e José de Alencar; e 
outra, na cidade de São Paulo (Faculdade de Direito de São Paulo), que contou com José Bento de Monteiro Lobato como um dos seus mais ilustres alunos.

Foi tão somente nos anos primeiros do século XX que a República Federativa do Brasil conheceu, de fato, as suas primeiras universidades. Há autores que asseveram ser a Universidade do Amazonas a mais antiga, visto ter sido fundada em 17 de janeiro de 1909, em pleno apogeu do comércio da borracha, na região amazônica. Não obstante, outros historiadores divergem da versão anterior e afirmam ser a Universidade Federal do Paraná a mais antiga, embora tenha sido fundada em 19 de dezembro de 1912. Por fim, uma terceira versão nos dá conta de que teria sido a Universidade do Brasil (atual Universidade Federal do Rio de Janeiro) a mais antiga, pois esta foi oficialmente criada em 7 sete de setembro de 1920, através de ato do então Presidente Epitácio Lindolfo da Silva Pessoa.

No entanto, com o cenário posterior à II Guerra Mundial, no qual as mulheres começaram a assumir os postos de trabalhos vacantes por conta das mortes dos combatentes varões, a Universidade ocidental iniciou guinada rumo à democratização do acesso, pelo menos na Europa e nos Estados Unidos.

No Brasil essas mudanças somente chegaram a partir do final dos anos 1960, como resultado dos intensos movimentos estudantis sob a forte influência do Maio de 1968', que resultou, por exemplo, na primeira reforma do nosso Sistema de Educação Superior, ainda sob a égide do Regime Militar. Desse modo, a Universidade brasileira passou a adotar como critério de seleção dos futuros alunos o grau de conhecimento destes em áreas do conhecimento humano, consideradas fundamentais, quais sejam: a língua portuguesa, a matemática, a física, a química, a biologia, a história, a geografia e, posteriormente, as línguas estrangeiras. Havia sido criado, portanto, o popular Vestibular, que se constituiu num procedimento de seleção de alunos baseado na aplicação de testes ou provas objetivas ${ }^{2}$ de rendimento. Seu intuito, como há pouco afirmado, era selecionar os futuros universitários com base na mensuração dos conhecimentos acumulados por estes durante os anos de escolarização formal. Nesse contexto histórico, conhecimento era sinônimo de significativa oportunidade de inserção na Universidade brasileira.

1 O Maio de 68 mudou profundamente as relações entre raças, sexos e gerações na França, e, em seguida, no restante da Europa e da América. No decorrer das décadas, as manifestações ajudaram o Ocidente a fundar ideias como as das liberdades civis democráticas, dos direitos das minorias, e da igualdade entre homens e mulheres, brancos e negros, heterossexuais e homossexuais. As ocupações de universidades se multiplicaram a partir da França; ocorreu a expansão das mobilizações entre os trabalhadores europeus e latino-americanos, em muitos casos em aliança com os estudantes universitários.

2 Estes instrumentos de medida do grau de aprendizagem discente (conhecidos como testes ou provas de rendimento) fundamentavam-se em modelos matemáticos, agrupados sob o rótulo técnico de Teoria Clássica dos Testes (TCT). Tais modelos garantiam a estimação de parâmetros métricos que revelavam aspectos qualitativos destes instrumentos de medida, dentre os quas é possível destacar a validade de construto, a fidedignidade e o grau de dificuldade. Com respeito aos itens que o compunham, destacam-se como características qualitativas a dificuldade, a discriminação e a homogeneidade. 


\section{A universidade brasileira do século XXI}

No entanto, a partir de meados dos anos 1990, com o advento da Sociedade da Informação, o conhecimento passou a ser um elemento secundário para o exercício profissional, visto ser um sensivel às rápidas mudanças científicas e aos avanços tecnológicos. Ademais, adquiriu uma característica adicional: a portabilidade individual. Cabe aclarar, neste momento, por oportuno: qualquer cidadão pode portar consigo os conhecimentos da humanidade e as últimas descobertas científicas, desde que tenha acesso às novas tecnologias.

Para ilustrar o que foi asseverado acima, recorramos a duas situações factíveis. A primeira delas, na qual um cidadão porta um pen-drive contendo toda a Enciclopédia Britânica, metido no bolso de sua calça jeans. A segunda situação, na qual um jovem aluno de doutorado faz download ou "baixa" um artigo científico, com a mais recente descoberta da engenharia genética: a indução da vida através de material inorgânico. São dois exemplos de que atualmente o conhecimento está, literalmente, ao alcance das mãos, e que pode ser portado por qualquer pessoa.

Não obstante, se o conhecimento está tão acessivel e popularizado entre os grupos sociais, então, qual o aspecto que diferencia os indivíduos bem-sucedidos social, educacional e profissionalmente? Eureca: o modo como estas pessoas usam esse conhecimento, essas informações. Eis surgir, assim, a Sociedade da Informação. Nesse novo modelo social, os indivíduos são induzidos a usar de modo inteligente, inovador, criativo e racional, as informações e os conhecimentos oriundos das descobertas científicas e tecnológicas, com vistas à resolução de problemas científicos, tecnológicos, sociais, profissionais e educacionais.

Ademais, essa sociedade passou a requerer profissionais que soubessem trabaIhar em grupo, de modo a cooperar com os demais colegas; que promovessem a inovação tecnológica através de um conjunto de competências de ordem superior, caracterizadoras da criatividade humana; que contribuíssem com os avanços científicos através do exercício da racionalidade científica, mas também da reflexão filosófica; que promovessem a resolução dos graves problemas sociais, econômicos e educacionais a afetar o nosso país, mas também todo o planeta; e que buscassem alcançar a tolerância e o bom convívio entre as sociedades, respeitando as diferenças entre os indivíduos e entre os grupos sociais.

Portanto, um novo indivíduo surgiu para ocupar espaços criados e demandados por uma nova sociedade. Diante das constatações relatadas, cabe à Universidade cumprir o papel de formar este novo indivíduo para este novo mundo, baseando as suas ações de formação no desenvolvimento de novas competências para a vida social e para o mundo do trabalho, os dois senhores aos quais à Universidade cabe servir. 


\section{Uma nova universidade para um novo Brasil}

A universidade brasileira atravessou os anos de 1990 até a primeira década de 2000 nesse cenário de novas e crescentes demandas, oriundas da sociedade da informação e do mercado de trabalho, bem como de desafios em nível mundial, como é o caso da crise energética; da poluição ambiental; das mudanças climáticas que ocasionam catástrofes ambientais; das imigrações de populações oriundas de paises pobres para paises ricos e vice-versa, sobretudo após a crise econômica mundial, dentre muitos outros.

Ao se iniciar o séc. XXI, a Universidade brasileira foi afetada drasticamente por políticas públicas educacionais que fomentaram novo modelo de Financiamento do Sistema Federal de Educação Superior. As Instituições Federais de Ensino Superior (IFES) foram conduzidas aos rincões mais distantes das grandes urbes, de modo a atender a crescente demanda oriunda dessa sociedade, através do Plano de Reestruturação e Expansão das Universidades Federais (REUNI), criado em 2007. Entre 2003 e 2010 foram criadas 14 novas Universidades Federais, o que supõe aumento substantivo de 31\% referente às 45 Universidades Federais existentes até 2003.

Nessa esteira, e para complementar a importância do REUNI, a Universidade Federal do Ceará (UFC) praticamente duplicou o número de cursos de graduação entre 2003 e 2010. Nesse período, houve incremento de 53 para 103 cursos (quase 100\% de aumento), permitindo que a referida IFES se faça, atualmente, presente em municípios do interior cearense. Hoje a UFC possui cursos de Graduação em Sobral, na região norte do Estado; em Quixadá, na região central cearense; em Crato, em Juazeiro do Norte e em Barbalha, municípios cearenses da região do Cariri (sul do Estado).

Observamos, desse modo, que houve uma guinada substancial na visão do Governo Federal acerca da função social e estratégica da Universidade brasileira, percebida, agora, como motor do desenvolvimento nacional, através da indução da presença desta em regiões economicamente e socialmente carentes. Estariamos, pois, nos aproximando do lema idealizado pelo Prof. Antonio Martins Filho, fundador da UFC: "o universal pelo regional".

No entanto, o novo desafio que se apresenta à Universidade brasileira, bem como a UFC, está sintetizado na necessidade de garantir a entrada da maior quantidade possivel dos melhores alunos egressos do Ensino Médio. Como referido anteriormente, a sociedade brasileira sofreu transformações abrumadoras, por conta de um mundo com demandas diversificadas, mas também por conta de um novo cidadão, que emergiu depois de um quarto de século de exercício democrático em nosso pais, além de quase 16 anos de estabilidade monetária a partir da criação do Real. Este novo ente social está, em geral, mais exigente; mais esclarecido; melhor politizado; e cônscio dos seus direitos, dos seus deveres e da função social da educação. 
Constata-se, a partir de todo o exposto, que houve autêntica ruptura de paradigma educacional, no âmbito da Educação Superior brasileira. Seguramente duas políticas educacionais validem e corroborem esta última assertiva: o REUNI e o novo ENEM, a quem passamos a descrever, a partir deste momento.

\section{Breve histórico do ENEM}

Criado em 1998, o ENEM possui como objetivo avaliar o desempenho do estudante ao fim da escolaridade básica, visando a aferir o desenvolvimento das competências e habilidades necessárias ao exercicio pleno da cidadania. Podem participar do exame alunos que estão concluindo ou que já concluíram o ensino médio em anos anteriores. Na sua primeira edição o ENEM contou com um número relativamente pequeno de participantes: cerca de 115.600. Não obstante, em 2008 o ENEM atingiu a marca de 4.018 .050 de inscritos e 2.920 .560 presentes ao exame (KLEIN; FONTANIVE, 2009), alcançado patamar superior aos 4.600 .000 inscritos na edição de 2010 (cerca de 15\% de incremento com respeito a 2008).

Desde 2004, o ENEM é utilizado como critério de seleção para os estudantes que pretendem concorrer a uma bolsa no Programa Universidade para Todos (ProUni). Além disso, cerca de 539 Instituições de Ensino Superior (IES), já usam o resultado do exame como critério de seleção para o ingresso no ensino superior, seja complementando ou substituindo (total ou parcialmente) o vestibular.

Em 2010, o Ministério da Educação (MEC) apresentou uma proposta de reformulação do ENEM e sua utilização como forma de seleção unificada nos processos seletivos das Instituições Federais de Ensino Superior (IFES). No que tange ao novo ENEM, este é composto por testes de rendimento (provas) em quatro áreas do conhecimento humano, a saber: a) linguagens, códigos e suas tecnologias (incluindo redação); b) ciências humanas e suas tecnologias; c) ciências da natureza e suas tecnologias; e d) matemática e suas tecnologias. Cada grupo de testes será composto por 45 itens de múltipla escolha, aplicados em dois dias, constituindo, assim, um conjunto de 180 itens. A redação deverá ser feita em língua portuguesa e estruturada na forma de texto em prosa do tipo dissertativo-argumentativo, a partir de um tema de ordem social, científica, cultural ou política.

A principal diferença do novo ENEM com respeito ao antigo modelo reside no fato de que, até 2008, a prova era composta por 63 itens interdisciplinares, sem articulação direta com os conteúdos ministrados no ensino médio, e sem a possibilidade de comparação das notas dos alunos, de um ano para outro. 0 novo ENEM permite a comparação dos desempenhos dos candidatos ao longo do tempo, possibilitando, assim, a organização de séries históricas de rico valor educacional. 0 novo exame será composto por perguntas objetivas em quatro áreas do conhecimento: linguagens, códigos e suas tecnologias (incluindo redação); ciências humanas e suas tecnologias; 
ciências da natureza e suas tecnologias e matemáticas e suas tecnologias. Cada grupo de testes será composto por 45 itens de múltipla escolha, aplicados em dois dias.

A utilização do novo ENEM como forma de seleção unificada nos processos seletivos das Instituições Federais de Ensino Superior (IFES) tem como principais objetivos democratizar as oportunidades de acesso às vagas federais de ensino superior, possibilitar a mobilidade acadêmica e induzir a reestruturação dos currículos do ensino médio.

Nesse âmbito há que esclarecer que as IFES possuem autonomia e, como tal, poderão optar entre quatro possibilidades de utilização do novo ENEM como processo seletivo, a saber:

- Como fase única, com o sistema de seleção unificada, informatizado e on-line;

- Como primeira fase;

- Combinado com o vestibular da instituição;

- Como fase única para as vagas remanescentes do vestibular.

Nesse âmbito, foi criado o Sistema de Seleção Unificada (Sisu), que é um sistema informatizado, gerenciado pelo MEC, por meio do qual as IFES participantes selecionarão novos estudantes exclusivamente pela nota obtida no ENEM de 2009.

Feita essa breve descrição acerca do ENEM, apresentaremos, a seguir, 12 motivos favoráveis à adoção do referido modelo avaliativo pelas Instituições Federais de Ensino Superior (IFES).

\section{Motivos favoráveis ao ENEM}

Motivo 1: A sociedade do século XXI, conhecida sob o rótulo de Sociedade da Informação e do Conhecimento, é caracterizada por conviver com crenças e valores plurais, pelo afã democrático e pela presença das Tecnologias da Informação e da Comunicação (TIC), em quase todas as partes e atividades. Esta sociedade é também marcada pelas profundas transformações decorrentes do rápido e constante avanço científico e tecnológico. Para os indivíduos que a compõem (os cidadãos) se Ihes exige fazer uso racional, inteligente, criativo e inovador das informações e conhecimentos resultantes dos rápidos avanços científicos, do desenvolvimento tecnológico e da produção artística e intelectual.

Motivo 2: A Universidade do século XXI, enquanto instituição educacional que serve à sociedade, e que é afetada por esta, através de suas crises e de suas transformações (BOAVENTURA SANTOS, 1995), busca responder às novas demandas. Assim, a Universidade trata de se adequar a receber estudantes com o perfil destacado acima: que saibam fazer uso racional, inteligente, criativo e inovador das informações resultantes dos avanços científicos, do desenvolvimento tecnológico e da pro- 
dução artística e intelectual. Para tal, a Universidade tem que rever, obrigatoriamente, os seus antigos processos seletivos (tais como o vestibular), pois estes se fundamentavam na escolha de outra tipologia de estudante: aquele que detém conhecimento baseado nos conteúdos escolares formalmente ensinados durante o ensino fundamental e médio.

Motivo 3: 0 ENEM é um modelo de seleção de estudantes concebido para avaliar habilidades e competências humanas, isto é, um procedimento seletivo adaptado às exigências dessa nova sociedade. As habilidades se referem às aptidões intrinsecas aos humanos. Por exemplo: o Homem possui a habilidade de respirar, de caminhar, de mover os braços, etc. As competências se referem às capacidades aprendidas e que estão fundadas em habilidades. Por exemplo: o Homem pode adquirir a competência de nadar, através do aprendizado de técnicas de controle da respiração, de movimentos harmonizados de braços e pernas, etc.

Logicamente, o ENEM busca avaliar competências mais complexas, tais como: domínio de linguagens (implica em dominar a norma culta da língua portuguesa e fazer uso da linguagem matemática, artística e científica); compreensão de fenômenos (supõe a construção e aplicação de conceitos das várias áreas do conhecimento para a compreensão de fenômenos naturais, de processos histórico-geográficos, da produção tecnológica e das manifestações artísticas); enfrentamento de situações-problema (implica em selecionar, organizar, relacionar, interpretar dados e informações representadas de diferentes formas, para tomar decisões e enfrentar situações-problema); construção de argumentações (modo supõe o relacionamento de informações, representadas em diferentes formas, e conhecimentos disponiveis em situações concretas, para construir argumentação consistente); elaboração de propostas (implica em recorrer aos conhecimentos desenvolvidos na escola para elaboração de propostas de intervenção solidária na realidade, respeitando os valores humanos e considerando a diversidade sociocultural). Estas competências devem ser desenvolvidas através da mediação da escola, de a que sejam empregadas pelos futuros universitários, sobretudo com vistas à geração de novos conhecimentos científicos, proposição de ações factíveis para resolver problemas sociais, promoção da inovação tecnológica, dentre outras.

Motivo 4: Os avanços científicos verificados, sobremaneira, após a $2^{\text {a }}$ guerra mundial permitiram a avaliação educacional se consolidar como área científica. A Matemática Aplicada, a Estatística Avançada, a Informática e a Psicologia Cognitiva conformam um conjunto de áreas do saber humano, algumas das quais se caracterizam como Ciências, que dão base e solidez à avaliação educacional. Como se trata de modelo avaliativo, o ENEM se serve dos principios brindados por estas áreas para fundamentar a prova que o caracteriza. Por exemplo: os itens (as questões) componentes da prova são elaborados sob rígidos procedimentos pedagógicos, que se 
baseiam, por seu turno, em princípios da psicologia cognitiva baseada na resolução de problemas (problem solving); os itens são posteriormente analisados, com base em procedimentos qualitativos (análise semântica, verificação da associação à matriz de referência, etc.) e quantitativos (determinação de parâmetros métricos de dificuldade, de discriminação e de acerto ao acaso; análise do funcionamento diferencial do item, etc.), com o fim garantir qualidade mínima aos mesmos. As análises quantitativas dos itens componentes do ENEM se baseiam em modelos matemáticos agrupados sob o rótulo de Teoria da Resposta ao Item (TRI), cujo uso educacional se generalizou a partir dos anos 1960, por conta, sobretudo dos avanços da área da informática. Como a complexidade matemática no campo da TRI é enorme, o progresso vertiginoso das máquinas de processamento (microcomputadores) possibilitou a viabilização dos cálculos que o modelo TRI exige. Contando com o progresso das máquinas, foi possivel, a partir disto, o desenvolvimento de softwares apropriados para os tais cálculos.

Motivo 5: Do ponto de vista estritamente técnico, cabe destacar que os parâmetros métricos dos itens da prova do ENEM são determinados a partir de modelos matemáticos subjacentes à Teoria da Resposta ao Item (TRI). A TRI surgiu para tentar solucionar problemas graves da sua antecessora, a Teoria Clássica dos Testes (TCT) que ainda é usada para fundamentar as análises estatísticas nos Vestibulares brasileiros. Uma das mais graves limitações da TCT foi destacada pelo psicólogo norte-americano Louis Leon Thurstone (1928, p. 547):

Um instrumento de medida, na sua função de medir, não pode ser seriamente afetado pelo objeto de medida. $\mathrm{Na}$ extensão em que sua função de medir for assim afetada, a validade do instrumento é prejudicada ou limitada. Se um metro mede diferentemente pelo fato de estar medindo um tapete, uma pintura ou um pedaço de papel, então nesta mesma extensão a confiança neste metro como instrumento de medida é prejudicada. Dentro dos limites de objetos para os quais o instrumento de medida foi produzido, sua função deve ser independente das características do objeto.

Com o intuito de minimizar essa grave limitação, a TRI busca respeitar dois princípios distintos, porém complementares: a convergência e a separabilidade (ANDRIOLA, 2009). No âmbito deste artigo nos importa detalhar o primeiro deles. 0 princípio da convergência está fundamentado na ideia de que o instrumento utilizado para medir as competências discentes deve maximizar a probabilidade de escolher os melhores candidatos, independentemente de estes alunos serem submetidos a outros instrumentos de medida em outras situações de seleção. Em síntese: os resultados devem convergir para a escolha dos melhores candidatos, independente dos instrumentos de medida utilizados para tal. 
Outra limitação da TCT está fundamentada no fato de que os parâmetros dos itens de um teste dependem da amostra de sujeitos sob a qual foram determinados (ANDRIOLA, 2002). Assim, um item se torna mais difícil ou mais fácil pelo fato de a amostra ser composta por sujeitos com maior ou menor grau de informações que são oriundas da aprendizagem formal, proporcionada pela escola. Desta forma, o parâmetro de dificuldade do item vai variar em função da amostra de sujeitos; dizse então, que a dificuldade do item é dependente dos sujeitos utilizados (subjectdependent). Estes dois graves problemas ilustrados são, ambos, solucionados pela TRI (PASQUALI; PRIMI, 2003).

Motivo 6: Os itens (questões) componentes da prova do ENEM buscam avaliar as habilidades e as competências, a partir de problemas cuja solução não depende unicamente do domínio do conhecimento formal do aluno sobre os conteúdos escolares. As questões apresentam informações que, per si, permitem ao candidato interpretar, inferir, deduzir, comparar, julgar, aplicar e resolver o problema apresentado, deixando de focar exclusivamente o conhecimento dos conteúdos escolares, como o fazia 0 Vestibular. Sob essa nova ótica, não importa, unicamente, o que o aluno sabe, mas o que é capaz de fazer com um conjunto de informações que lhe é fornecido. A ideia é simples: o aluno terá que demonstrar suas competências para, a partir de informações que lhe foram apresentadas, empregá-las a contento com vistas a propor soluções factíveis para problemas que envolvem conteúdos curriculares.

Motivo 7: A prova do ENEM traduz, ainda, a preocupação por abordar a integração nacional, visto compormos uma República Federativa. Isto se dá através da apresentação de itens (questões) que enfocam peculiaridades regionais, que dão ênfase às riquezas naturais, culturais e históricas, que destacam os problemas sociais e que propõem reflexões acerca das possiveis respostas ou saidas às dificuldades e/ou problemas brasileiros. Com este princípio se deseja passar duas mensagens. A primeira delas diz respeito à imensa riqueza cultural do nosso país, que deve ser conhecida, para que, assim possa ser respeitada, preservada e divulgada às futuras gerações. A segunda é proporcionar maior conhecimento acerca da heterogeneidade histórica, social, linguística, cultural, étnica, que conforma uma federação unificada pela língua. Esse é o país que deve ser melhor conhecido pelos futuros líderes sociais, políticos,econômicos e empresariais que emergirão das nossas universidades.

Motivo 8: 0 modelo do ENEM induz o Ensino Médio a adotar uma proposta pedagógica centrada no desenvolvimento de competências relevantes para o cidadão dessa nova sociedade. Retira-se, desse modo, o foco principal de formação do aluno com base na aquisição de conhecimentos e no domínio de conteúdos escolares, como se faz no atual modelo de Ensino Médio. Conforme assevera Boaventura Santos ([2004?], p. 78-79): 
Os critérios de avaliação devem ser congruentes com os objetivos da reforma [universitária], nomeadamente com as tarefas de legitimação e com a valorização das transformações na produção e na distribuição do conhecimento e suas ligações às novas alternativas pedagógicas.

Sob esse prisma, o Ensino Médio deverá enforcar o desenvolvimento de competências que possibilitem os alunos enveredarem nas áreas tecnológicas, na pesquisa científica ou mesmo no mundo do trabalho. Há que se propor alternativas viáveis para aqueles que não desejam ou que não têm mérito para adentrar os muros da Universidade. Cabe ao Ensino Médio pavimentar essas novas vias e ao MEC criar essas novas alternativas.

Motivo 9: Como o ENEM faz parte do Sistema de Seleção Unificada (SISU), que foi desenvolvido pelo Ministério da Educação (MEC) para selecionar os candidatos às vagas das Instituições Federais de Ensino Superior (IFES) que utilizem a nota do Exame Nacional do Ensino Médio como única fase de seu processo seletivo, a adoção do ENEM por estas instituições de ensino permitirá que os candidatos concorram às vagas oferecidas pelo Sistema Federal de Ensino Superior. Cabe destacar que, nesta primeira edição do SISU, 51 IFES ofereceram 47.913 vagas em bacharelados, licenciaturas e cursos superiores de tecnologia. Para ilustrar essa nova possibilidade, instaurada pelo ENEM, o egresso do Ensino Médio do Ceará, não estará concorrendo unicamente às mais de 6.000 vagas oferecidas pelas IFES do seu Estado (somente a UFC ofereceu 5.724 vagas). 0 egresso do ensino Médio estará concorrendo às quase 80.000 vagas disponibilizadas pelo Sistema Federal de Ensino Superior, através do SISU (o aluno terá duas opções para escolha do curso superior). Tal fato significa dotar 0 candidato de maior oportunidade para ingressar no referido sistema, desde que 0 aluno demonstre ter desenvolvido as competências avaliadas pelo ENEM.

Motivo 10: Já que as vagas das várias IFES se destinam ao Sistema Federal de Educação Superior, haverá a possibilidade de promover maior mobilidade regional dos candidatos aprovados, aspecto extremamente salutar ao desenvolvimento da graduação brasileira. Ora, cumpre destacar, nesse momento, que a ideia de mobilidade acadêmica fez-se presente na gênese da universidade ocidental, com a Universidade de Bolonha (Itália), em 1088. Nessa época, o caráter universal denotava não apenas a procedência de sua clientela, oriunda de todas as partes da Europa, mas também a natureza da licença e do direito de ensinar, bem como praticar as profissões liberais em qualquer parte da Cristandade. Outro ponto a ser ressaltado: a Pós-Graduação (stricto sensu) brasileira está firmemente atrelada ao princípio da mobilidade acadêmica e científica. Sob esta égide, os cientistas brasileiros são formados em paises mais desenvolvidos que o Brasil e retornam com maior valor agregado, contribuindo, assim, para o desenvolvimento científico e regional do nosso país. Como resultado, o Brasil é atualmente o $13^{\circ}$ colocado no ranking de paises de maior produção intelectual, contribuindo com $2 \%$ do conhecimento científico mundial. 
Por outro lado, a mobilidade regional permitirá aos futuros profissionais conhecer rincões distantes das suas regiões de origem; ter acesso à riqueza da gastronomia e da cultura popular, presentes nesses lugares; identificar os mais graves problemas da nossa República Federativa e, assim, proporcionar reflexões acerca dos nossos potenciais para solucioná-los a contento; criar uma identidade nacional, com bases nessas experiências, aspecto extremamente salutar para as futuras gerações de brasileiros.

Motivo 11: Logicamente que a mobilidade acadêmica idealizada para os universitários da graduação deverá estar pautada em ações de assistência estudantil de maior monta e de envergadura nacional, pois conforme Pacheco e Ristoff (2004, p. 9): "Estudo do Observatório Universitário da Universidade Cândido Mendes revela que 25\% dos potenciais alunos universitários são tão carentes que não têm condições de entrar no ensino superior, mesmo se ele for gratuito".

No entanto, cumpre destacar que a Pós-Graduação (stricto sensu) brasileira conta, desde há muito, com agências nacionais de fomento, tais como: a Coordenação de Aperfeiçoamento de Pessoal de Nivel Superior (CAPES) e o Conselho Nacional de Desenvolvimento Científico e Tecnológico (CNPq). Além destas, há as agências estaduais. Todas elas oferecem bolsas de mestrado, de doutorado e de pós-doutorado, de modo a custear a ida e a manutenção dos estudantes brasileiros em outras regiões do nosso país, ou ao exterior deste. Desse modo, políticas voltadas à assistência à mobilidade e à residência ou alojamento estudantil, direcionadas aos alunos de graduação, deverão ser planejadas e imediatamente implementadas pelo MEC, de modo a garantir o usufruto pleno por parte do aluno universitário desta nova e relevante possibilidade de formação, amparada no intercâmbio regional e na interação social.

Motivo 12: Caso o Sistema de Educação Superior brasileiro venha a ser "oxigenado" com esse novo contingente de universitários (selecionados a partir das habilidades e competências para a resolução de problemas), que poderá vir a estar em interação com as peculiaridades regionais (através da mobilidade acadêmica), o Brasil estará preparando-se melhor para afrontar um grave problema: a baixa proporção de jovens entre 18 e 24 inseridos no sistema universitário, que atualmente ronda 13\%. Vale a pena realçar: essa proporção é inferior ao valor observado em alguns países latino-americanos (México, Chile, Argentina e Uruguai, por exemplo), e muito inferior à proporção de universitários existente na Europa, na América do Norte e em países da Ásia (Japão e os "Tigres Asiáticos"). Cumpre destacar, ademais, que um dos objetivos do Plano Nacional de Educação (PNE), era prover, até o final de década, a oferta de Educação Superior para, pelo menos $30 \%$ da faixa etária de 18 a 24 anos (BRASIL, 2001). 


\section{À guisa de conclusão}

Conforme publicação decorrente da Conferência Mundial sobre Ensino Superior (2009), realizada em Paris, em julho de 2009, o Ensino Superior deve ser concebido como um bem público, de valor estratégico para todos os demais niveis de educação. Diante da complexidade dos desafios mundiais, a Educação Superior tem a responsabilidade social de avançar nosso conhecimento multifacetado sobre várias temáticas que envolvem dimensões culturais, científicas, econômicas e sociais. Deve, ainda, levar a sociedade a gerar conhecimento global para responder aos desafios mundiais, com relação à segurança alimentar, às mudanças climáticas, ao uso consciente da água, ao diálogo intercultural, às fontes de energia renovável e à saúde pública.

Apesar dessa importância estratégica, a Educação Superior padece de problemas e de disparidades, que persistem e constituem fonte de desigualdade e iniquidade. Um dos problemas enfrentados pela Educação Superior está na expansão do acesso, com garantias mínimas de qualidade da formação. Qualidade educacional requer a institucionalização de processos periódicos de avaliação, de modo a obterem-se dados acerca do alcance dos objetivos institucionais e das metas estabelecidas.

Ademais desses problemas mundiais, há que se dar relevo ao fato de o Brasil necessitar aumentar, urgentemente, a proporção de jovens universitários entre $18 \mathrm{e}$ 24 anos, com base em um novo perfil de estudante, e de acordo com as novas demandas sociais, educacionais e tecnológicas. Caso isso não venha o ocorrer, o pais estará fadado a sofrer consequências nefastas, dificultando, sobremaneira, o desenvolvimento nacional, a justiça social e a inserção internacional. Nesse âmbito, o ENEM nos brinda essa perspectiva: aumentar a oportunidade de jovens com competências e habilidades, de modo a que estes passem a integrar o Sistema Federal de Educação Superior, incrementando substancialmente a proporção de universitários brasileiros.

Não obstante, fazem-se necessárias algumas ponderações acerca do que foi descrito neste artigo. Para tal, farei uso de algumas ideias do filósofo e escritor espanhol Baltasar Gracián y Morales (1601 - 1658), que em sua obra El arte de la prudencia, do ano 1647, fazia referências à triade prudência, parcimônia e ousadia. Creio que essa triade pode ser aplicada ao foco do nosso texto, pois parece ser óbvio que o ENEM não será a panacéia para o Ensino Superior, muito menos para os graves problemas enfrentados pelo Ensino Médio. Portanto, haveremos que ter prudência quanto às potencialidades e vantagens do novo ENEM.

Dessa forma, merecem destaque três aspectos adicionais, pois embora devam ser perseguidos, incansavelmente e garantidos integralmente pelo MEC, há que serem seguidos de certa dose de parcimônia e ousadia. 0 primeiro desses aspectos diz respeito à seleção dos futuros universitários, que deverá estar pautada no mérito. Ao analisarmos este tema na pós-graduação (stricto sensu) nos daremos conta de 
que os alunos desse nível de ensino são rigorosamente selecionados com base na meritocracia. Assim, uma primeira lição deve ser aprendida: a expansão da graduação não pode abrir mão da qualidade dos futuros universitários, que é assegurada pela seleção baseada na meritocracia.

Ainda com respeito à seleção, o ENEM possibilita que os candidatos sem condições financeiras de arcar com os custos de deslocamento para o município que centraliza as atividades de seleção participem do certame seletivo. Isto porque as provas do novo ENEM são aplicadas no local em que os candidatos se inscreveram, possibilitando, desse modo, que jovens sem condições de custear seu deslocamento possam comprovar ter mérito para adentrar o espaço universitário. Trata-se, portanto, de uma logística inteligentíssima, que se baseia numa regra de ouro: tratar diferentemente os diferentes, permitindo, assim, a inclusão social através da maximização da oportunidade de esses alunos participarem de um processo seletivo, com vistas ao ingresso em uma universidade brasileira, de natureza pública.

0 segundo aspecto fundamenta-se na garantia de financiamento da mobilidade estudantil, com base nas necessidades econômicas e na meritocracia. A partir desses dois critérios, o MEC deverá agraciar os alunos com bolsas de mobilidade, de modo a garantir a equidade do processo formativo. Logicamente que durante todo o processo formativo, e de forma periódica, os bolsistas terão que honrar a ajuda recebida através, por exemplo, de desempenhos acadêmicos adequados e aceitáveis, com base em critérios mínimos de qualidade estabelecidos pelo MEC, pela IFES e/ou pelos gestores do curso. Pode-se vislumbrar, ademais, que os universitários exerçam as suas atividades de estágio em comunidades carentes dos municípios nos quais estejam inseridos, honrando, assim, com uma função relevante da Universidade brasileira, qual seja: a extensão. Como resultado, temos uma segunda lição a ser aprendida: a mobilidade estudantil permitirá incrementar ações de extensão, possibilitando, ademais, que os universitários conheçam realidades e peculiaridades sociais diversas, agregando valor à formação.

0 terceiro e último aspecto diz respeito à prestação de contas (accountability) através de procedimentos de avaliação da formação dos alunos, dos cursos e das IES. Uma vez mais, utilizemos o exemplo da pós-graduação (stricto sensu), que atingiu níveis elevadissimos de qualidade, com base em sistemáticas avaliativas rotineiras, muito bem delineadas, com critérios claros, conhecidos e aceitos pela comunidade acadêmica. Além disso, os resultados dessas avaliações deverão gerar consequências visiveis para as IES, para os cursos, para os docentes e para os próprios discentes, como ocorre corriqueiramente na pós-graduação (stricto sensu), com o intuito primordial de aprimoramento. A terceira lição que se pode retirar: a formação estudantil e todas as ações que a conformam devem ser avaliadas corriqueiramente, e os resultados devem gerar consequências, sobretudo com vistas ao aperfeiçoamento do próprio processo formativo. 
Finalmente, e para concluir, cabe destacar o maior potencial do novo ENEM: poderá vir a contribuir com o Exame Nacional do Desempenho Estudantil (ENADE), desde que haja comunalidade mínima entre ambos. 0 problema desta proposta reside no fato de que o ENEM tem como objetivo central avaliar o desempenho do estudante ao fim da escolaridade básica, visando aferir o desenvolvimento das competências e habilidades necessárias ao exercício pleno da cidadania. Já o ENADE avalia o rendimento dos alunos de graduação (ingressantes e concludentes) em relação aos conteúdos programáticos dos cursos (Componente Específico), e ao nivel de informação e de atualização com respeito à realidade brasileira e mundial (Componente Geral).

Para criar comunalidade mínima entre esses dois processos avaliativos, o ENADE poderia vir a utilizar itens para avaliar competências e habilidades necessárias ao egresso universitário para o exercício pleno da profissão e da cidadania, igualmente como o faz o ENEM com os egressos do ensino médio. Caso isso fosse feito, teríamos possibilidade de obter medidas sistemáticas do desenvolvimento de competências e de habilidades dos alunos, ao longo da sua formação universitária. Ademais, seria possivel, desse modo, estimar o valor agregado pelo curso e/ou pela IES ao desenvolvimento das competências e habilidades referidas, ou seja, obter indícios sobre a eficiência e a eficácia do processo formativo dos cursos universitários em potencializar essas relevantes características cognitivas. Convém ressaltar, nesse momento, uma sábia frase do teólogo inglês William George Ward (1812-1882): "Há os que se queixam do vento, os que esperam que ele mude de direção e os que procuram ajustar as velas da nau". Ajustemos as nossas velas. 


\section{Referências}

ANDRIOLA, W. B. Detección del Funcionamiento Diferencial del Ítem (DIF) en tests de rendimiento: aportaciones teóricas y metodológicas. 2002. 529 f.Tese (Doutorado) - Universidad Complutense de Madrid, Madrid, 2002.

Psicometria moderna: caracteristicas e tendências. Estudos em Avaliação Educacional, São Paulo, v. 20, p. 319-340, 2009.

BOAVENTURA SANTOS, S. Pela mão de Alice: o social e o político na pós-modernidade. São Paulo: Cortez, 1995.

A universidade do século XXI: para uma reforma democrática e emancipatória da universidade. Brasília, DF, [2004?]. Disponível em: <http://www.ces.uc.pt/ bss/documentos/auniversidadedosecXXI.pdf>. Acesso em: 17 mar. 2010.

BRASIL. Ministério da Educação. Plano Nacional de Educação - PNE: subsídios para a elaboração dos planos estaduais e municipais de educação. Brasilia, DF, 2001. Disponivel em: <http://www.inep.gov.br/download/cibec/2001/titulos_avulsos/ miolo_PNE.pdf>. Acesso em: 17 mar. 2010.

CONFERÊNCIA MUNDIAL SOBRE ENSINO SUPERIOR, 1., 2009, Paris. As novas dinâmicas do ensino superior e pesquisas para a mudança e o desenvolvimento social: comunicado. Paris: UNESCO, 2009. Disponivel em: <http://aplicweb.feevale.br/ site/files/documentos/pdf/31442.pdf>. Acesso em: 2 mar. 2010.

KLEIN, R.; FONTANIVE, N. Uma nova maneira de avaliar as competências escritoras na redação do ENEM. Ensaio: avaliação e políticas públicas em educação, Rio de Janeiro, v. 17, n. 65, p. 585-598, out./dez. 2009.

PACHECO, E.; RISTOFF, D. I. Educação superior: democratizando o acesso. Brasilia: INEP, 2004. (Série documental. Textos para discussão).

PASQUALI, L.; PRIMI, R. Fundamentos da Teoria da Resposta ao Item (TRI). Avaliação Psicológica, Porto Alegre, v. 2, n. 2, p. 99-110, 2003.

THURSTONE, L. L. Attitudes can be measured. American Journal of Sociology, Chicago, IL, n. 33, p. 529-554, 1928.

Recebido em: 17/03/2010

Aceito para publicação em: 16/10/2010 